\title{
No Ink on Ductal Carcinoma In Situ: A Single Centre Experience
}

\author{
PIERO FREGATTI ${ }^{1}$, MARCO GIPPONI ${ }^{1}$, FRANCESCA DEPAOLI ${ }^{1}$, FEDERICA MURELLI ${ }^{1,2}$, \\ MARINA GUENZI ${ }^{3}$, ELISABETTA BONZANO ${ }^{3}$, MARCELLO CEPPI $^{4}$ and DANIELE FRIEDMAN ${ }^{1,2}$ \\ ${ }^{1}$ Breast Surgery Unit, Ospedale Policlinico San Martino, Genoa, Italy; \\ ${ }^{2}$ University of Genoa, School of Medicine, Genoa, Italy; \\ ${ }^{3}$ Radiotherapy Unit, Ospedale Policlinico San Martino, Genoa, Italy; \\ ${ }^{4}$ Epidemiology Unit, Ospedale Policlinico San Martino, Genoa, Italy
}

\begin{abstract}
Background/Aim: A retrospective analysis of 388 patients with pure ductal carcinoma in situ (DCIS) was performed in order to test the correlation of clearance margin of resection and other host-, tumor-and treatmentrelated factors with ipsilateral breast tumor recurrence (IBTR). Materials and Methods: The pathological analysis was performed according to a standardized protocol: positive margins had DCIS at the inked margin; close margins had tumor between 0.1 to $0.9 \mathrm{~mm}$, or 1 to $1.9 \mathrm{~mm}$, and negative margins were $\geq 2 \mathrm{~mm}$. Results: At a median follow-up of 90 months there were 26 IBTR (10 invasive and 16 DCIS). Both in univariate and multivariate analysis a significant difference was observed in IBTR by comparing positive versus close/negative margins of excision $(p=0.05)$ and the number of re-operations $(p=0.000)$. Moreover, the actuarial IBTR rates were significantly different in patients with a positive compared to close/negative margins (log-rank test, $p=0.042$ ) while the stratification by the margin width (0.1-0.9 mm; 1.0-1.9 mm; $\geq 2 \mathrm{~mm}$ ) was not significant (logrank test, $p=0.243)$. Conclusion: The policy of "no ink on the tumor" can be translated from invasive to DCIS, because the actuarial IBTR rates were significantly different only in patients with a positive, compared to close/negative margins.
\end{abstract}

In the last decades, the incidence of ductal carcinoma in situ (DCIS) of the breast has greatly increased thanks to the widespread use of screening mammography, accounting for approximately $15-25 \%$ of newly-diagnosed breast cancers (1-2). Its biological nature coupled with the virtual absence of regional and systemic metastases allows to achieve high

Correspondence to: Marco Gipponi, MD, Breast Unit - Ospedale Policlinico San Martino, L.go R. Benzi, 10, 16132 Genoa, Italy. E-mail: marco.gipponi@hsanmartino.it

Key Words: Breast cancer, DCIS, margin of excision. specific survival rates from $98 \%$ up to $100 \%$ with either mastectomy or breast-conserving surgery (BCS), that is lumpectomy followed by radiation therapy (RT) (3).

The primary aim of surgery is to prevent local recurrence by achieving a clear margin of resection; in this peculiar clinical setting, however, the aim of radical excision should be carefully counterbalanced by the cosmetic results that might be challenged by repeated re-excision. As a matter of fact, the extent of the excision margin is an ongoing topic of debate; while a negative margin may be more than enough for invasive breast cancer, according to the policy that defines "no ink on the tumor", the extent of excision is much less defined in DCIS (4). Recent clinical studies would suggest that an excision margin of 1 to $2 \mathrm{~mm}$ is not associated with an increased rate of recurrence as compared to a margin of more than $2 \mathrm{~mm}$, while some others suggest a margin of at least $2 \mathrm{~mm}(5,6)$. Moreover, clinical, biological and therapeutic variables, such as young age, necrosis, nuclear grade, and post-operative RT regimen may be related to the rate of local recurrence (7-9).

Given these controversies and the paucity of data regarding the safe distance of the nearest margin of excision in pure DCIS, a retrospective analysis of patients undergoing surgery for DCIS in a large single center was performed in order to assess the association of margin widths of $<1 \mathrm{~mm}, 1$ to $2 \mathrm{~mm}$, and $>2 \mathrm{~mm}$ with ipsilateral breast tumor recurrence (IBTR) considering also the potential role of host-, tumor- and treatment-related factors.

\section{Materials and Methods}

From 2000 to 2016, 388 patients diagnosed with DCIS without any histologic evidence of microinvasion who underwent BCS with or without post-operative RT at the Breast Unit of "Ospedale Policlinico San Martino" in Genoa were selected. A preoperative core biopsy was performed for histologic diagnosis of DCIS; moreover, imaging examinations were obtained to define the site and extent of disease as well as for the preoperative localization of 
DCIS. The aim of the operation was an en bloc excision of the DCIS area with a $1 \mathrm{~cm}$ macroscopic margin. The operative specimen was oriented both with clips for the post-operative radiography that was systematically performed in order to confirm complete removal of the imaging abnormality, and with sutures for the pathologic examination. Where appropriate, further tissue was removed from margins considered clinically or radiographically to be involved. The surgical procedure was completed with the clipping of the primary tumor site.

The pathologic analysis was always performed according to a standardized protocol including: inking, slicing at regular interval ( $3 \mathrm{~mm}$ ), and paraffin embedding of the whole specimen; the radial margin width and the amount of disease approaching the margin (focal/minimal or extensive/multiple foci margin involvement) were described. Surgical margins were considered to be involved if there was DCIS present at the inked margin; close (although negative) margins were considered to have tumor cells between 0.1 to $0.9 \mathrm{~mm}$, or 1 to $1.9 \mathrm{~mm}$, and negative margins were $\geq 2 \mathrm{~mm}$. Only patients with positive margins underwent re-excision unless it had been already performed during the primary operation; if there was no residual disease at the time of re-excision, the margin was considered to be negative. Post-operative whole breast radiation (WBR) was given in 255 patients with standard scheme (50 Gy over 25 fractions in 5 weeks) or with a hypofractionated radiobiologically equivalent schedule. In both the schemes, high risk patients (G3, hormone receptor negative, close or focally positive margins) had a boost dose to the primary tumor site identified by the clips positioned by the surgeon. Other 110 patients did not undergo post-operative WBR due to patient's refusal, advanced age, well differentiated DCIS, or serious co-morbidity factors. Moreover, 47 patients with hormone-receptor positive DCIS and associated risk factors such as size $>2 \mathrm{~cm}$, high grade, and young age ( $<50$-year-old women) had adjuvant endocrine therapy (letrozole $2.5 \mathrm{mg} /$ day or tamoxifen $20 \mathrm{mg} /$ day) for 5 years

Clinical and pathologic features of DCIS were collected, such as: age at diagnosis, imaging pattern, DICS subtype, grading, histologic size, width of excision margins, hormonal receptor status, postoperative radiotherapy, number of operations, and type of histologic recurrence (in situ or invasive). Local recurrences were always treated by means of skin-sparing or nipple-sparing mastectomy. Each patient underwent annual clinical and imaging (mammography, sonography, breast magnetic resonance, etc.) follow-up for at least five years.

Statistical methods. Univariate analysis was used to correlate clinical and pathologic factors in patients with or without IBTR by means of Fisher's exact test. A Cox proportional hazard regression model was used to assess the independent significance of variables. The time to events was measured from the date of primary surgery. The univariate analysis of the recurrence and survival outcomes was performed using the Kaplan-Meier estimation method and log rank test $(10,11)$.

\section{Results}

Overall, 388 patients with pure DCIS were included in the present analysis; the median age was 61 years, with an age range of 36 to 94 years. Eighteen patients had a positive radial margin at the primary operation, with negative reexcision margins; 46 and 14 patients had close margins of
Table I. Clinical, pathologic, and treatment-related variables according to IBTR (Univariate analysis, Fisher's exact Test).

\begin{tabular}{|c|c|c|c|c|c|}
\hline & \multicolumn{4}{|c|}{ IBTR } & \multirow[b]{3}{*}{$\begin{array}{c}\text { Fisher's } \\
\text { Exact } \\
\text { Test }(p)\end{array}$} \\
\hline & \multicolumn{2}{|c|}{ No } & \multicolumn{2}{|c|}{ Yes } & \\
\hline & N. & $\%$ & $\mathrm{~N}$. & $\%$ & \\
\hline Age at operation & & & & & 0.392 \\
\hline $33-49$ years & 87 & 89.6 & 10 & 10.4 & \\
\hline $50-58$ years & 91 & 93.8 & 6 & 6.2 & \\
\hline $59-68$ years & 94 & 96.9 & 3 & 3.1 & \\
\hline $69-91$ years & 90 & 92.7 & 7 & 7.3 & \\
\hline Mammographic pattern & & & & & 0.920 \\
\hline Microcalcificazions & 217 & 93.1 & 16 & 6.9 & \\
\hline Mass & 87 & 93.5 & 6 & 6.5 & \\
\hline Microcalcifications + Mass & 36 & 94.7 & 2 & 5.3 & \\
\hline Others & 5 & 100.0 & 0 & 0.0 & \\
\hline Unknown & 17 & 88.5 & 2 & 11.5 & \\
\hline DCIS subtype & & & & & 0.119 \\
\hline Din $1 \mathrm{C}$ & 49 & 92.4 & 4 & 7.6 & \\
\hline Din 2 & 182 & 93.3 & 13 & 6.7 & \\
\hline Din 3 & 121 & 95.2 & 6 & 4.8 & \\
\hline Unknown & 10 & 76.9 & 3 & 23.1 & \\
\hline Grading & & & & & 0.425 \\
\hline 1 & 62 & 93.9 & 4 & 6.1 & \\
\hline 2 & 188 & 93.5 & 13 & 6.5 & \\
\hline 3 & 112 & 92.5 & 9 & 7.5 & \\
\hline Histologic size & & & & & 0.653 \\
\hline$<2 \mathrm{~cm}$ & 245 & 93.8 & 16 & 6.2 & \\
\hline $2.1-5 \mathrm{~cm}$ & 103 & 92.8 & 8 & 7.2 & \\
\hline$>5 \mathrm{~cm}$ & 14 & 87.5 & 2 & 12.5 & \\
\hline Clearance margin & & & & & \\
\hline Positive & 14 & 77.7 & 4 & 22.3 & 0.05 \\
\hline Close/Negative (0.1-0.9 mm) & 45 & 97.8 & 1 & 2.2 & \\
\hline Close/Negative (1.0-1.9 mm) & 14 & 100.0 & 0 & 0.0 & \\
\hline Negative $(\geq 2 \mathrm{~mm})$ & 289 & 93.2 & 21 & 6.8 & \\
\hline ER status & & & & & 1.000 \\
\hline Positive (>10\%) & 210 & 93.3 & 15 & 6.7 & \\
\hline Negative $(<10 \%)$ & 152 & 93.2 & 11 & 6.8 & \\
\hline PgR status & & & & & 0.842 \\
\hline Positive (>10\%) & 186 & 93.0 & 14 & 7.0 & \\
\hline Negative $(<10 \%)$ & 176 & 93.6 & 12 & 6.4 & \\
\hline Endocrine therapy & & & & & 1.000 \\
\hline No & 305 & 93.0 & 23 & 7.0 & \\
\hline Tamoxifene & 45 & 93.8 & 3 & 6.2 & \\
\hline Letrozole & 9 & 100.0 & 0 & 0.0 & \\
\hline No. of operations & & & & & 0.000 \\
\hline 1 & 276 & 97.1 & 8 & 2.9 & \\
\hline 2 or more & 86 & 82.7 & 18 & 17.3 & \\
\hline Post-operative WBR & & & & & 0.826 \\
\hline No & 103 & 93.6 & 7 & 6.4 & \\
\hline Yes & 236 & 92.5 & 19 & 7.5 & \\
\hline Unknown & 23 & 100.0 & 0 & 0.0 & \\
\hline
\end{tabular}

IBTR: Ipsilateral breast tumor recurrence; ER: estrogen receptor; PgR: progesteron receptor.

0.1 to $0.9 \mathrm{~mm}$ and 1 to $1.9 \mathrm{~mm}$, respectively; 310 patients had negative margins $(\geq 2 \mathrm{~mm})$. There were 26 IBTR, 10 $(38.5 \%)$ were invasive and the remaining $16(61.5 \%)$ were 
Table II. Multivariate analysis (Cox regression analysis).

\begin{tabular}{|c|c|c|c|c|c|}
\hline & Recurrence $(\mathrm{N})$ & Patients (N) & Hazard Ratio & Confidence Interval 95\% & Log-rank test $(p)$ \\
\hline Age at operation & & & & & 0.162 \\
\hline $33-49$ years & 10 & 97 & 1.00 & Ref. & \\
\hline $50-58$ years & 6 & 97 & 0.21 & $0.04-0.99$ & \\
\hline $59-68$ years & 3 & 97 & 0.22 & $0.04-1.28$ & \\
\hline $69-91$ years & 7 & 97 & 0.69 & $0.18-2.63$ & \\
\hline Mammographic pattern & & & & & 1.000 \\
\hline Microcalcifications & 16 & 233 & 1.00 & Ref. & \\
\hline Masss & 6 & 93 & 0.38 & $0.10-1.47$ & \\
\hline Microcalcifications + Mass & 2 & 38 & 0.31 & $0.05-1.97$ & \\
\hline Others & 0 & 5 & 0.00 & - & \\
\hline $\mathrm{ND}$ & 2 & 19 & 4.18 & $0.37-47.20$ & \\
\hline DCIS subtype & & & & & 0.082 \\
\hline Din $1 \mathrm{C}$ & 4 & 53 & 1.00 & Ref. & \\
\hline Din 2 & 13 & 195 & 8.38 & $0.64-110.23$ & \\
\hline Din 3 & 6 & 127 & 2.36 & $0.17-33.57$ & \\
\hline Unknown & 3 & 13 & 26.79 & $1.40-512.73$ & \\
\hline Grading & & & & & 0.178 \\
\hline 1 & 4 & 66 & 1.00 & Ref. & \\
\hline 2 & 13 & 201 & 1.08 & $0.88-1.67$ & \\
\hline 3 & 9 & 121 & 1.25 & $1.02-3.92$ & \\
\hline Histologic size & & & & & 0.217 \\
\hline$<2 \mathrm{~cm}$ & 16 & 261 & 1.00 & Ref. & \\
\hline $2.1-5 \mathrm{~cm}$ & 8 & 111 & 1.51 & $1.15-1.97$ & \\
\hline$>5 \mathrm{~cm}$ & 2 & 16 & 2.12 & $1.21-5.43$ & \\
\hline Clearance margin & & & & & 0.002 \\
\hline Positive & 4 & 18 & 17.99 & $3.51-92.15$ & \\
\hline Negative & 22 & 370 & 1.00 & Ref & \\
\hline ER status & & & & & 0.723 \\
\hline Positive (>10\%) & 15 & 225 & 1.00 & Ref. & \\
\hline Negative $(<10 \%)$ & 11 & 163 & 1.34 & $026-6.82$ & \\
\hline PgR status & & & & & 0.614 \\
\hline Positive (>10\%) & 14 & 200 & 1.00 & Ref. & \\
\hline Negative $(<10 \%)$ & 12 & 188 & 1.60 & $0.26-9.75$ & \\
\hline Endocrine therapy & & & & & 0.145 \\
\hline No & 23 & 328 & 1.00 & Ref. & \\
\hline Tam & 3 & 48 & 0.44 & $0.08-2.40$ & \\
\hline Letrozole & 0 & 9 & 0.00 & - & \\
\hline No. of operations & & & & & $<0.001$ \\
\hline 1 & 8 & 284 & 1.00 & Ref. & \\
\hline 2 or more & 18 & 104 & 17.04 & $4.94-58.82$ & \\
\hline Post-operative WBR & & & & & 0.432 \\
\hline No & 7 & 110 & 1.00 & Ref. & \\
\hline Yes & 19 & 255 & 1.48 & $1.21-2.18$ & \\
\hline Unknown & 0 & 23 & 0.00 & - & \\
\hline
\end{tabular}

IBRT: Ipsilateral breast tumor recurrence; ER: estrogen receptor; PgR: progesteron receptor.

non-invasive; IBTR occurred in 4 out of 18 patients $(22.2 \%)$ with initially positive margins of excision; in one out of 46 patients $(2.1 \%)$ with close margins $(0.1-0.9 \mathrm{~mm})$; no IBTR occurred in 14 patients with close margins (1-1.9 mm), and 21 IBTR were reported in 310 patients $(6.7 \%)$ with negative margins $(>2 \mathrm{~mm})$. The association between IBTR and the clinical, pathological, and treatment variables are reported in Table I. In univariate analysis there was a significant difference in IBTR by comparing positive versus close/negative margins of excision $(p=0.05)$ and the number of re-operations $(p=0.000)$. On multivariate analysis, after controlling for age, mammographic findings, DCIS subtype, size, grading, hormone receptor status, endocrine therapy, and post-operative WBR, both the margin status $(p=0.002)$ and the number of re-operations $(p<0.001)$ were significantly associated with IBTR (Table II). 


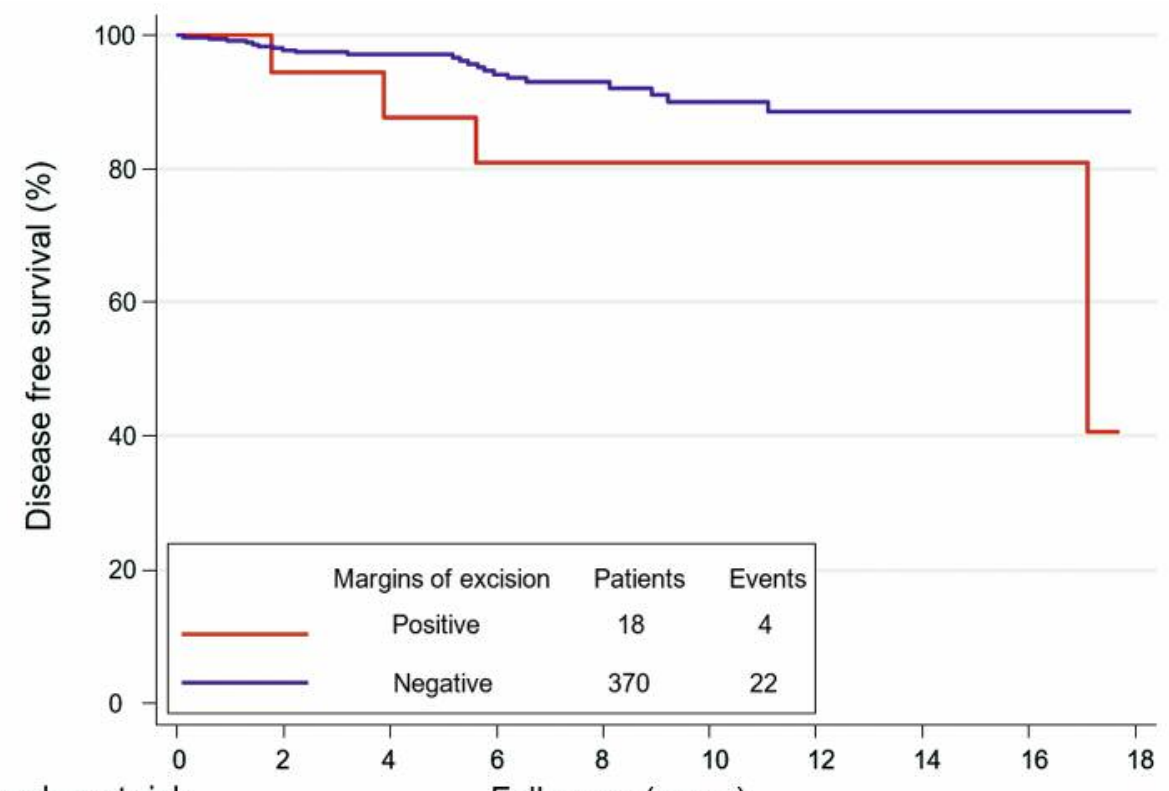

Number at risk

Follow-up (years)

$\begin{array}{lcccccccccc}\text { Positive } & 18 & 16 & 13 & 11 & 10 & 6 & 3 & 3 & 2 & 0 \\ \text { Negative } & 370 & 331 & 248 & 176 & 107 & 73 & 46 & 22 & 3 & 0\end{array}$

Figure 1. Kaplan-Meier local control according to margin status (log-rank test for equality of survivor functions: $p=0.042$ ).

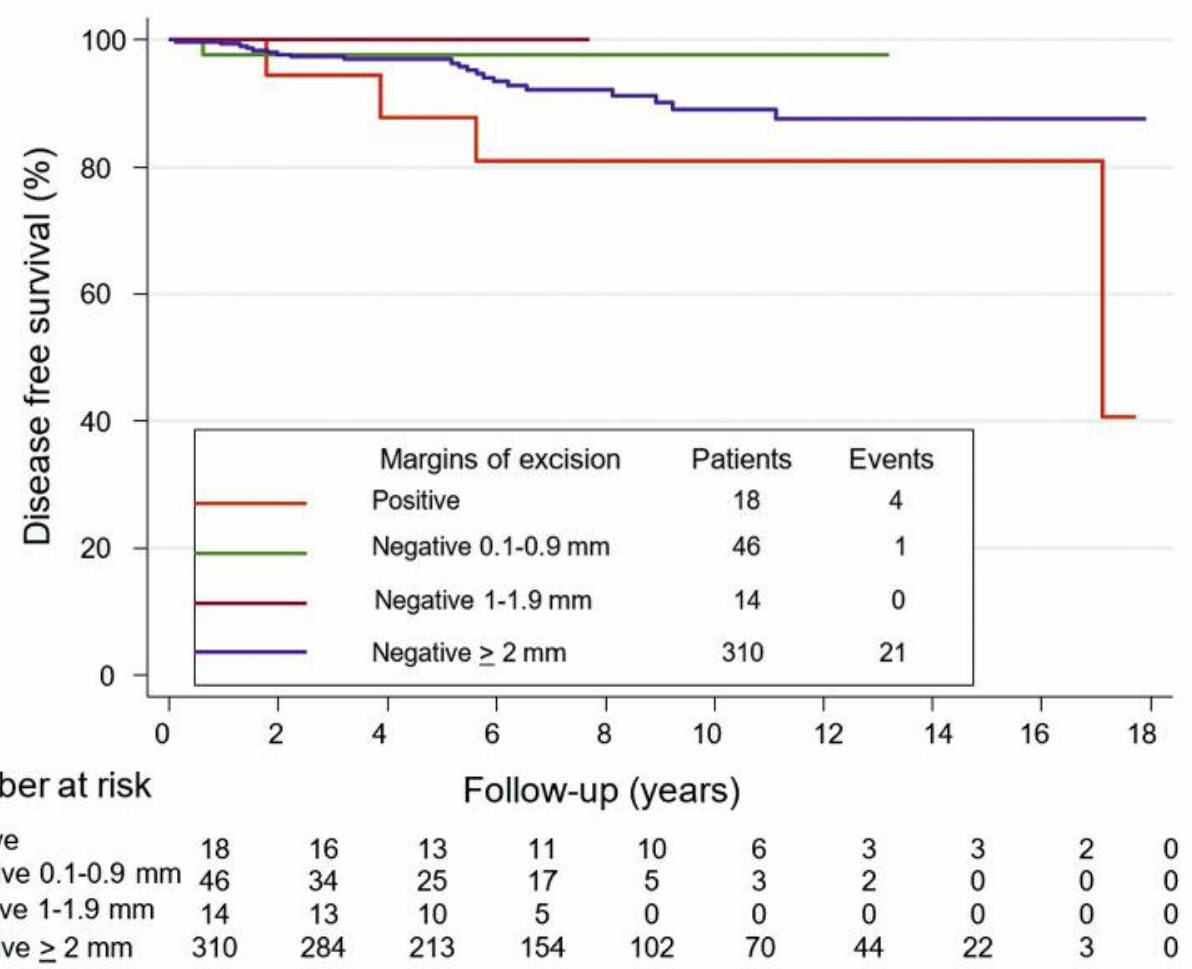

Figure 2. Kaplan-Meier local control according to the clearance margin: 0.1-0.9 mm; 1-1.9 mm, and $\geq 2 \mathrm{~mm}$ (log-rank test for equality of survivor functions: $p=0.243$ ). 


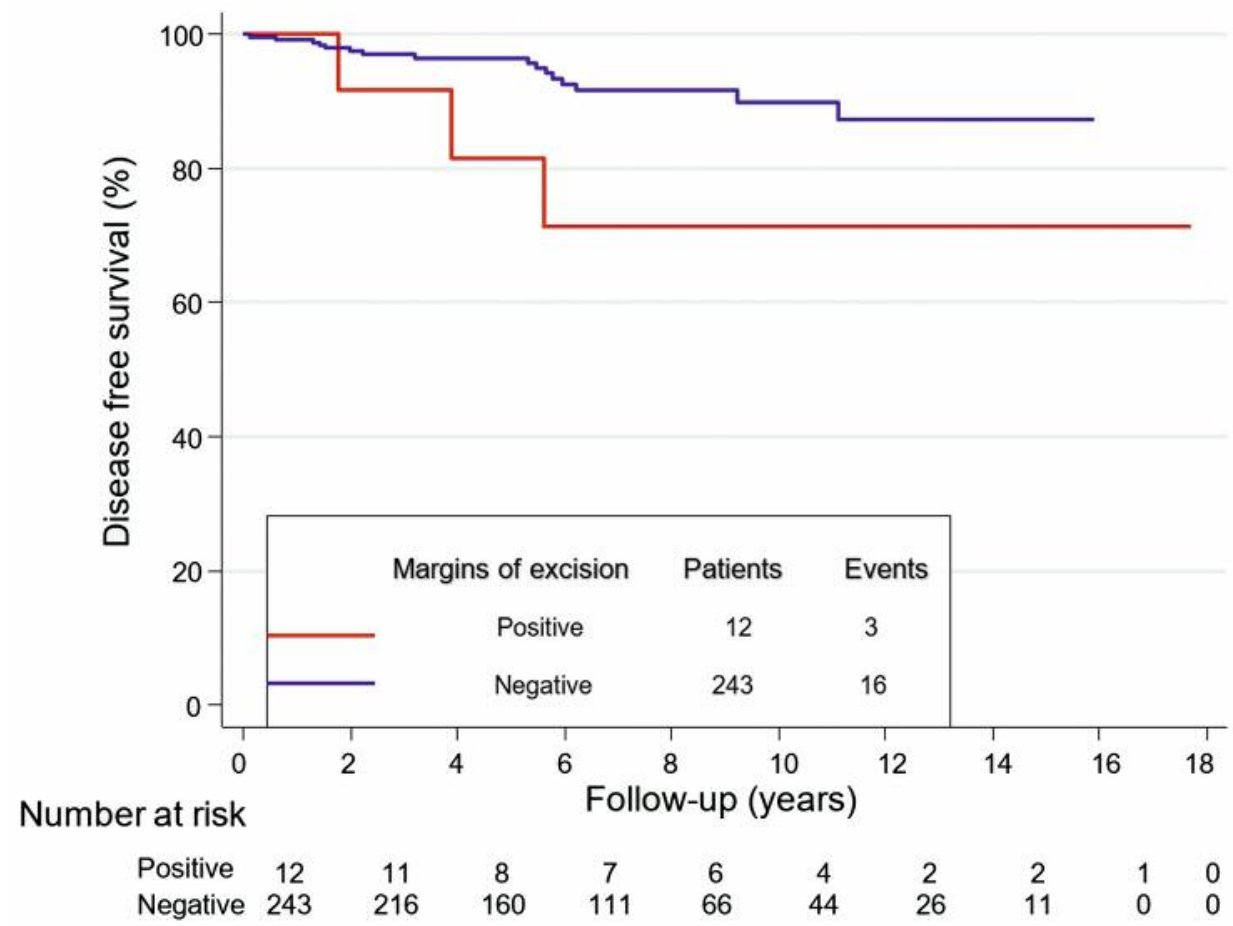

Figure 3. Kaplan-Meier local control according to margin status in 255 patients undergoing post-operative WBR (log-rank test for equality of survivor functions: $p=0.049$ ).

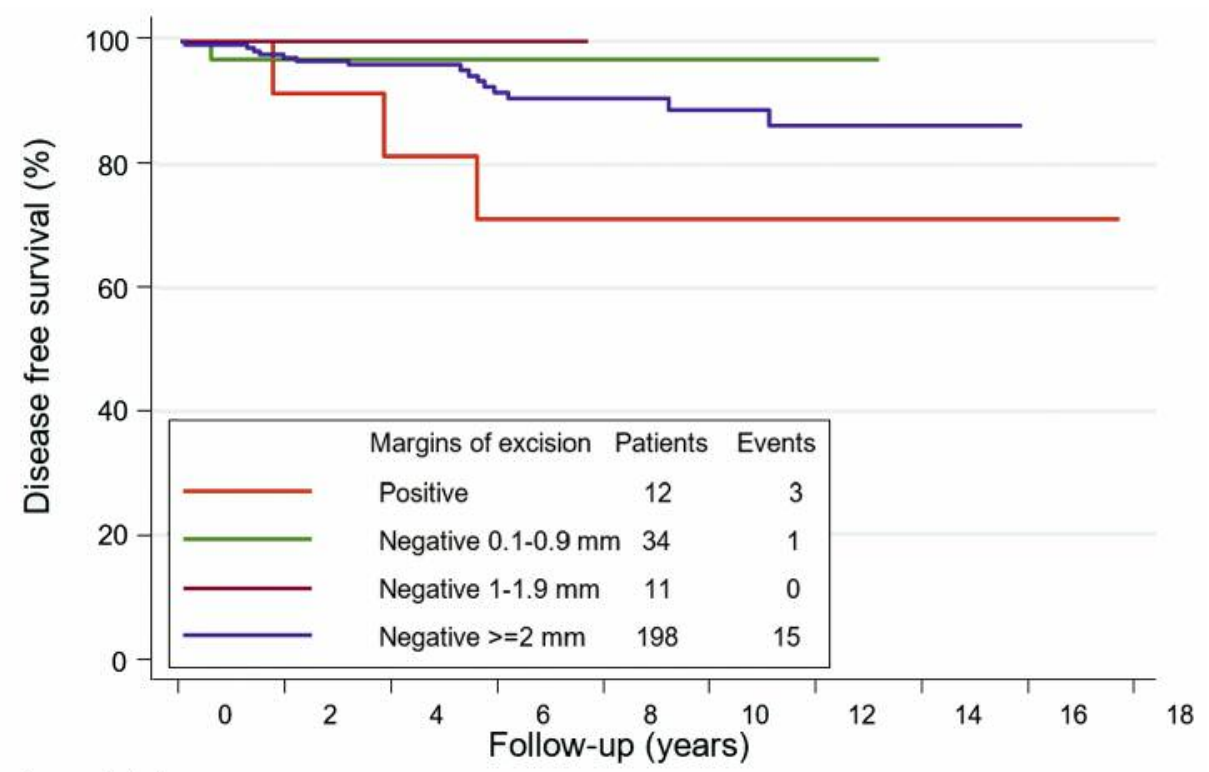

\begin{tabular}{|c|c|c|c|c|c|c|c|c|c|c|}
\hline \multicolumn{11}{|l|}{ Number at risk } \\
\hline Positive & 12 & 11 & 8 & 7 & 6 & 4 & 2 & 2 & 1 & 0 \\
\hline Negative $0.1-0.9 \mathrm{~mm}$ & 34 & 23 & 18 & 10 & 3 & 1 & 1 & 0 & 0 & 0 \\
\hline Negative $1-1.9 \mathrm{~mm}$ & 11 & 11 & 8 & 3 & 0 & 0 & 0 & 0 & 0 & 0 \\
\hline Negative $>=2 \mathrm{~mm}$ & 198 & 182 & 134 & 98 & 63 & 43 & 25 & 11 & 0 & 0 \\
\hline
\end{tabular}

Figure 4. Kaplan-Meier local control according to the clearance margin in 255 patients undergoing post-operative WBR (log-rank test for equality of survivor functions: $p=0.204$ ). 
At a median follow-up of 90 months (range $=12-189$ months) the actuarial IBTR rates were significantly different in patients with a positive margin of excision at the primary operation as compared to patients with close/negative margins (log-rank test, $p=0.042$ ) while the stratification by the margin width $(0.1-0.9 \mathrm{~mm} ; 1.0-1.9 \mathrm{~mm} ; \geq 2 \mathrm{~mm})$ was not significant (log-rank test, $p=0.243$ ) (Figures 1 and 2). No significant difference was observed in IBRT in patients who underwent or not post-operative WBR (7.5\% versus 6.4\%; Fisher's exact test, $p=0.826$ ). Moreover, in the group of patients who underwent post-operative WBR (the most representative as for sample size and number of events) IBTR rates were significantly different in patients with a positive margin of excision at the primary operation as compared to patients with close/negative margins (log-rank test: $p=0.049$ ) while no significant difference was observed based on the clearance margin (log-rank test: $p=0.204$ ) (Figures 3 and 4).

\section{Discussion}

IBTR has rather serious economic, physical, and psychological implications for a growing number of asymptomatic women with screen-detected tumors, especially if one considers that more than a half of these recurrences are represented by invasive breast cancer. Several clinical, pathological, and treatment-related variables are related to the local control of DCIS such as: young age; mammographic pattern; tumor size; necrosis; nuclear grade; DCIS subtype; excision margins, and post-operative RT regimen $(7-9,12-17)$. Of these, margin status is the only factor that can be controlled by the surgeon, and the primary aim, of surgery is just the prevention of local recurrence by achieving microscopic free margins of excision, as it is traditionally recommended in practice guidelines (18-20). For these reasons, patients with extensive/multiple foci margin involvement and/or evidence of residual malignant appearing calcifications on post-operative mammography should undergo re-excision, if cosmetically feasible, or mastectomy, especially when there is margin involvement after repeated re-excision (21).

Conversely, an area of controversy regards focal/minimal margin involvement and close margins or resection, that is $>0 \mathrm{~mm}$ to $<2 \mathrm{~mm}$. As to the former, the clinical experience of Monteau et al. (22) in carefully selected patients with close $(<2 \mathrm{~mm})$ or focally/minimally involved margins suggests that re-excision may be avoided because a satisfactory local control rate can be achieved by increasing the post-operative radiation dose to the tumor bed to at least 66 Gy. This policy is substantially shared by the Practice Guidelines of MD Anderson Cancer Center because only patients with $<2 \mathrm{~mm}$ margins who are not planned to receive radiotherapy undergo additional surgery for wider margins of resection (21).
With regards to close margins, the DCIS meta-analysis of Marinovich et al. (6) indicated that patients with margins of $\geq 2 \mathrm{~mm}$ had a significantly lower rate of local recurrence than patients with margins $<2 \mathrm{~mm}$; moreover, margin distance above $2 \mathrm{~mm}$ was not associated with further reduction of odds of local recurrence compared to $2 \mathrm{~mm}$. Hence, the consensus statement that followed this meta-analysis proposed a $2 \mathrm{~mm}$ margin as the standard of treatment in DCIS undergoing BCS (23). However, other clinical experiences suggested that close although negative margins ( $>0$ to $2 \mathrm{~mm}$, or $>1 \mathrm{~mm}$ ) may be enough, even regardless whether patients received radiotherapy $(5,24)$.

In the current study, a significant difference $(p=0.002)$ in IBTR in a comparison of positive versus close/negative margins of excision was observed even after controlling for age, mammographic findings, DCIS subtype, size, grading, hormone receptor status, endocrine therapy, and postoperative WBR; moreover, IBTR rates were not significantly different after stratification by the margin width (0.1-0.9 $\mathrm{mm} ; 1.0-1.9 \mathrm{~mm} ; \geq 2 \mathrm{~mm}$ ) both in the overall group of patients (log-rank test, $p=0.243$ ) and in those who selectively underwent post-operative WBR (log-rank test: $p=0.204)$.

On these grounds, the oncological relevance of the clearance margins should be discussed considering, firstly, if there is an actual different biological behavior between DCIS and invasive breast cancer; secondly, why an initial positive margin maintains its negative prognostic role even after reexcision with clear margin. As regards the clearance margin in invasive cancer, the consensus panel of experts, based on the results of the meta-analysis of BCS in this subset of patients, concluded that margins of $>0 \mathrm{~mm}$ are sufficient to determine a negative margin when performing BCS, according to the policy "no ink on the tumor" (25-26). However, in patients undergoing BCS for invasive breast cancer, the disease that is most frequently found closest to the margin of excision is just DCIS (27). Hence, a single clearance margin should be clearly stated, no matter whether the disease is invasive or in situ. In agreement with the Practice Guidelines of MD Anderson Cancer Center, our findings would suggest to reduce this margin as for invasive breast cancer, that is "no ink on the tumor", whenever postoperative WBR is planned; accordingly, the radiation boost dose should be properly tailored based on the final surgical margin status $(21,22)$.

This would allow to improve the cosmetic results by avoiding unnecessary wide excision at the primary operation, cavity shave margins for removing systematically normal breast tissue that is uninvolved by DICS, or re-excision due to close, although negative margins $(21,28)$. As a matter of fact, it has been calculated that a cancer of $1.6 \mathrm{~cm}$ in diameter has a volume of $2.1 \mathrm{ml}$ and to excise this tumor volume with $3 \mathrm{~mm}$ margins would yield a specimen volume of $5.6 \mathrm{ml}$ while to excise this same tumor with $10 \mathrm{~mm}$ margins would increase 
the specimen volume to $24.4 \mathrm{ml}$, that is a four-fold volume increase (29). As we know, the specimen volume is one of the main determinants of the cosmetic outcome in BCT that relates to the ratio between excision volume, breast size, and the depth of the tumor site within the breast (30). So, any useless overtreatment should be carefully avoided in order to improve the cosmetic outcome.

The other question regards the clinical relevance of an initial positive margin that maintains its negative prognostic value notwithstanding the re-excision margins are clearly negative, as we observed in our study. In such cases, a positive excision margin might not represent per se a suboptimal surgical technique but, likely, a different biologic disease because, as careful pathologic studies of mastectomy specimens have demonstrated by means of Egan's wholebreast-mount-technique, most breast cancers have a multifocal/multicenter distribution and these microscopic foci can be found in $42-47 \%$ even beyond $2 \mathrm{~cm}$ margins of excision (31-32). So, when IBTR does occur, it should be primarily related to an intrinsic cell-resistance to radiation therapy of these multifocal sites although, at present, such failures cannot a priori be predicted in order to proceed directly to mastectomy. In other words, an initially positive margin of excision would represent a marker of increased risk of local relapse more than the true determinant of recurrence.

As other clinical experiences, the potential weakness of this study is represented by the retrospective analysis of a single-center study with a rather small number of patients if compared to the samples included in previous meta-analyses. This might be, however, one of its potential points of strength due to the homogeneity of definitions, diagnostic work-up, treatment schedules regarding both surgery and radiotherapy, microscopic assessment of the radial margin of excision, and follow-up procedures. Moreover, adjuvant endocrine therapy was given to a limited number of patients, thus avoiding any protective effect on surgical margins regarding IBTR.

\section{Conclusion}

This study did not demonstrate an increase in IBRT rates for close $(0.1$ to $1.9 \mathrm{~mm})$ as compared with negative $(\geq 2 \mathrm{~mm})$ radial margins of excision thus suggesting that the policy of "no ink on the tumor" that is well accepted for invasive breast cancer could be translated to DCIS, especially in patients undergoing post-operative WBR with adequate boost dose to the primary tumor site.

\section{References}

1 National Institutes of Health State-of-the-Science Conference Statement: Diagnosis and Management of Ductal Carcinoma In Situ (DCIS). http://consensus.nih.gov/2009/dcis.htm (Accessed on April 05, 2012).
2 Joslyn SA: Ductal carcinoma in situ: trends in geographic, temporal, and demographic patterns of care and survival. Breast J 12: 20-27, 2006 .

3 Ernster VL, Barclay J, Kerlijkowske K, Wilkie H and BallardBarbash R: Mortality among women with ductal carcinoma in situ of the breast in the population-based surveillance, epidemiology and end results program. Arch Intern Med 160: 953-958, 2000.

4 Adams BJ, Zoon CK, Stevenson C, Chitnavis P, Wolfe L and Bear HD: The role of margin status and re-excision in local recurrence following breast conservation surgery. Ann Surg Oncol 20: 2250-2255, 2013.

5 Shaikh T, Li T, Murphy CT, Zaorsky NG, Bleicher RJ, Sigurdson ER, Carlson R, Hayes SB and Anderson P: Importance of surgical margin status in ductal carcinoma in situ. Clinical Breast Cancer 16: 312-318, 2016.

6 Marinovich ML, Azizi L, Macaskill P, Irwig L, Morrow M, Solin LJ and Houssami N: The association of surgical margins and local recurrence in women with ductal carcinoma in situ treated with breast-conserving therapy: meta-analysis. Ann Surg Oncol 23: 3811-3821, 2016.

7 Keslin LL, Goldstein NS, Lacerna MD, Balasubramaniam M, Martinez AA, Rebner M, Pettinga J, Frazier RC and Vicini FA: Factors associated with local recurrence of mammographically detected ductal carcinoma in situ of the breast in patients given breast-conserving therapy. Cancer 88: 596-607, 2000.

8 Vicini FA and Recht A: Age at diagnosis and outcome for women with ductal carcinoma in situ of the breast: a critical review of the literature. J Clin Oncol 20: 2736-2744, 2002.

9 Fisher ER, Dignam J, Tan-Chiu E, Costantino J, Fisher B, Paik $\mathrm{S}$ and Wolmark N: Pathologic findings from the National Surgical Adjuvant Breast Project (NSABP) eight-year update of Protocol B-17: intraductal carcinoma. Cancer 86: 429-438, 1999.

10 Kaplan EL and Meier P: Nonparametric estimation from incomplete observations. J Am Stat Assoc 53: 457-481, 1958.

11 Peto R, Pike MC, Armitage P, Breslow NE, Cox DR, Howard SV, Mantel N, McPherson K, Peto J and Smith PG: Design and analysis of randomized clinical trials requiring prolonged observation of each patient. II. Analysis and examples. Br J Cancer 35: 1-39, 1977.

12 Dillon MF, Mc Dermott EW, O'Doherty A, Quinn CM, Hill AD and O'Higgins $\mathrm{N}$ : Factors affecting successful breast conservation for ductal carcinoma in situ. Ann Surg Oncol 14: 1618-1628, 2007.

13 Ringberg A, Idvall I, Ferno M, Anderson H, Anagnostaki L, Boiesen P, Bondesson L, Holm E, Johansson S, Lindholm K, Ljungberg $\mathrm{O}$ and Ostberg $\mathrm{G}$ : Ipsilateral local recurrence in relation to therapy and morphological characteristics in patients with ductal carcinoma in situ of the breast. Eur J Surg Oncol 26: 444-451, 2000.

14 MacKenzie TA, Titus-Ernstoff L, Vacek PM, Geller B, Weiss JE, Goodrich ME and Carney PA: Breast density in relation to risk of ductal carcinoma in situ of the breast in women undergoing screening mammography. Cancer Causes Control 18: 939-945, 2007.

15 Holland R, Schuurmans Stekhoven JH, Hendriks JHCL, Vebeek AL and Mravunac M: Extent, distribution, and mammographic/ histological correlations of breast ductal carcinoma in situ. Lancet 335: 519-522, 1990. 
16 Castellano I, Marchio C, Tomatis M, Ponti A, Casella D, Bianchi S, Vezzosi V, Arisio R, Pietribiasi F, Frigerio A, Mano MP, Ricardi U, Allia E, Accortanzo V, Durando A, Bussolati G, Tot T and Sapino A: Micropapillary ductal carcinoma in situ of the breast: an inter-institutional study. Mod Pathol 23: 260-269, 2010.

17 NHS Cancer Screening Programmes: Uncertainties in the management of screen-detected ductal carcinoma in situ. NHSBSP Publication no. 66 July 2008. Sheffield, UK: NHS Cancer Screening Programmes, 2008.

18 The American College of Surgeons. Practice guideline for the management of ductal carcinoma in situ of the breast (DCIS). J Am Coll Surg 205: 145-161, 2007.

19 Olivotto I and Levine M: Steering Committee on Clinical Practice Guidelines for the Care and Treatment of Breast Cancer. Clinical practice guidelines for the care and treatment of breast cancer: the management of ductal carcinoma in situ (summary of the 2001 update). CMAJ 165: 912-913, 2001.

20 Cutuli B, Fourquet A, Luporsi E, Arnould L, Caron Y, Cremoux Pd, Dilhuydy JM, Fondrinier E, Fourme E, Giard-Lefevre S, Blanc-Onfroy ML, Lemanski C, Mauriac L, Sigal-Zafrani B, Tardivon A, This P, Tunon de Lara C, Kirova Y and Fabre N: Standards, Options and Recommendations for the management of ductal carcinoma in situ of the breast (DCIS): update 2004. Bull Cancer 92: 155-168, 2005.

21 Kuerer HM, Smith BD, Chavez-MacGregor M, Albarracin C, Barcenas CH, Santiago L, Edgerton ME, Rauch GM, Giordano SH, Sahin A, Krishnamurthy S, Woodward W, Tripathy D, Yang WT and Hunt KK: DCIS margins and breast conservation: MD Anderson Cancer Center Multidisciplinary practice guidelines and outtcomes. J Cancer 8: 2653-2662, 2017.

22 Monteau A, Sigal-Zafrani B, Kirova YM, Fourchotte V, Bollet MA, Vincent-Salomon A, Asselain B, Salmon RJ and Fourquet A: Ductal carcinoma in situ of the breast with close or focally involved margins following breast-conserving surgery: treatment with reexcision or radiotherapy with increased dosage. Int $\mathbf{J}$ Radiat Oncol Biol Phys 75: 1021-1028, 2009.

23 Morrow M, Van ZeeKJ, Solin LJ, Houssami N, ChavezMacGregor M, Harris JR, Horton J, Hwang S, Johnson PL, Marinovich ML, Schnitt SJ, Wapnir I and Moran MS: Society of Surgical Oncology - American Society for Radiation Oncology American Society of Clinical Oncology consensus guideline on margins for breast-conserving surgery with whole-breast irradiation in ductal carcinoma in situ. Pract Radiat Oncol 6: 287-295, 2016.
24 Ekatah GE, Turnbull AK, Arthur LM, Thomas J, Dodds C and Dixon JM: Margin width and local recurrence after breast conserving surgery for ductal carcinoma in situ. EJSO 43: 20292035, 2017

25 Houssami N, Macaskill P, Marinovich ML and Morrow M: The association of surgical margins and local recurrence in women with early-stage invasive breast cancer treated with breastconserving therapy: a meta-analysis. Ann Surg Oncol 21: 717730, 2014.

26 American Society of Breast Surgeons. The American Society of Breast Surgeons position statement on breast cancer lumpectomy margins. 2013. https://www.breastsurgeons.org/new layout/ about/statements/PDF_Statements/Lumpectomy_Margins.pdf.

27 Dixon JM, Newlands C, Dodds C, Thomas J, Williams LJ, Kunkler IH, Bing A and Macaskill EJ: Association between underestimation of tumor size by imaging and incomplete excision in breast-conserving surgery for breast cancer. Br J Surg 103: 830-838, 2016

28 Chagpar A, Yen T, Sahin A, Hunt KK, Whitman GJ, Ames FC, Ross MI, Meric-Bernstam F, Babiera GV, Singletary SE and Kuerer HM: Intraoperative margin assessment reduces reexcision rates in patients with ductal carcinoma in situ treated with breast-conserving surgery. Am J Surg 186: 371-377, 2003.

29 Wood WC: Close/positive margins after breast-conserving therapy: additional resection or no resection? Breast 22: S115S117, 2013.

30 Krekel N, Zonderhuis B, Muller S, Bril H, van Slooten HJ, de Lange de Klerk E, van den Tol P and Meijer S: Excessive resection in breast conserving therapy: a retrospective multicenter study. Breast J 17: 602-609, 2011.

31 Vaidya JS, Vyas JJ, Chinoy RF, Merchant N, Sharma OP and Mittra I: Multicentricity of breast cancer: whole-organ analysis and clinical implications. Br J Cancer 74: 820-824, 1996.

32 Holland R, Veiling S, Mravunac $M$ and Hendrics JHCL: Histologic multifocality of Tis, T1-2 breast carcinoma: implications for clinical trials of breast-conserving surgery. Cancer 56: 979-990, 1985. 